\title{
DIGITALCOMMONS
}

@WAYNESTATE -

Wayne State University

Administrative and Organizational Studies

College of Education

$1-1-2016$

\section{Uncertainty, Reflection, and Designer Identity Development}

Monica W. Tracey

Wayne State University, Monicatracey@wayne.edu

Alisa Hutchinson

Wayne State University, ahutchina@gmail.com

\section{Recommended Citation}

Tracey, M. W., \& Hutchinson, A. (2016). Uncertainty, reflection, and designer identity development. Design Studies, 42, 86-109. Available at: http://digitalcommons.wayne.edu/coe_aos/9

This Article is brought to you for free and open access by the College of Education at DigitalCommons@WayneState. It has been accepted for inclusion in Administrative and Organizational Studies by an authorized administrator of DigitalCommons@WayneState. 
Running Head: UNCERTAINTY AND DESIGNER IDENTITY

Uncertainty, reflection, and designer identity development

Monica W. Tracey, $\mathrm{PhD}^{1}$

Alisa Hutchinson, $\mathrm{MEd}^{2}$

${ }^{1}$ Corresponding author. Email: monicatracey@wayne.edu. Address: Instructional Technology

Department, College of Education, 369 Education, Wayne State University, Detroit, MI. Phone:

313-577-1700, fax: 313-577-1693.

${ }^{2}$ Email: alisa.hutchinson@wayne.edu. Address: Instructional Technology Department, College of Education, 355 Education, Wayne State University, Detroit, MI. Phone: 313-577-1700, fax: 313577-1693. 


\begin{abstract}
Uncertainty is a defining quality of the design space and it stands to reason that designers' personal attitudes toward uncertainty may influence design processes and outcomes via cognitive, affective, and/or behavioral channels. Individual attitudes and behavior patterns related to uncertainty may constitute a critical element of designer identity, which represents the synthesis of knowledge, action, and being. This qualitative study examined how graduate students in an instructional design course reflected on their experiences and beliefs regarding uncertainty. Participants were more reflective when discussing a general experience with uncertainty than their current attitudes toward uncertainty in design. Findings support the use of narrated reflection in design education related to uncertainty and identity. Implications for design education interventions and design are discussed.
\end{abstract}

Keywords: professional identity; design education; design processes; reflective practice; design research

\title{
Highlights:
}

1. This study positions uncertainty orientation as an element of designer identity.

2. The study examines reflection for identity development in relation to uncertainty.

3. Participants achieved higher levels of reflection when discussing a general experience.

4. Participants consistently failed to attend to emotional aspects of uncertainty.

5. Some participants altered their uncertainty orientation when reconsidering the topic later. 
Professional identity has been conceptualized as the synthesis of knowledge, action, and self, requiring not only the acquisition of expertise and skills but also professional ways of being (Dall'Alba, 2009; Tovey, Bull, \& Osmund, 2010). From this perspective, students in professional education programs need to establish a sense of who they are becoming as a professional - and imagine who they might be - as the context for the development of the knowledge and behaviors that are manifested via the professional self (Dall'Alba, 2009). For design students, this means that foundational learning (i.e., what design is and what designers do, both in general and discipline-specific) should not be seen as an end in itself but should instead be used to facilitate the establishment of a preliminary and personal sense of what it means to be a designer. For design educators, this raises provocative questions: What designerly ways of being might be most useful for the initial cultivation of designer selves? And what instructional strategies and experiences might be effective in giving students the space and resources to explore these ways of being in service of identity development?

As part of a long-term, design-based research project on design education, reflection, and professional identity, this study seeks to address these questions and contribute to emerging discourse on identity development in design by examining how graduate students in instructional design explored experiences with uncertainty using reflective writing. As a ground for our findings, we will first discuss the role of uncertainty in design and as well as pathways by which it may influence designer ways of being. We will also briefly outline the relationship between professional identity development and reflective writing in order to provide a rationale for incorporating this instructional strategy in design curricula.

\section{Uncertainty as a defining feature of design}

Uncertainty has been generically defined as a lack of adequate knowledge about events 
that may occur in the future or that may have already occurred but have not yet been revealed to the subject (Bar-Anan, Wilson, \& Gilbert, 2009; Rosen, Ivanova, \& Knäuper, 2014). This is consistent with everyday usage of the word: when we feel sure about a particular situation, we believe we can accurately predict what will happen next, while perceptions of uncertainty infuse the anticipation of events with doubt. It is typically thought people experience uncertainty as an aversive condition that they are motivated to reduce or eliminate (Bar-Anan et al, 2009). Uncertainty is also a defining feature of the design space, which is concerned with ill-structured or wicked problems that can be clarified and understood only through speculative attempts to solve them (Buchanan, 1982; Cross, 2011). As designers try (and fail) to develop solutions, they gain valuable insight into the nature and boundaries of the original problem (Dorst \& Cross, 2001) and thus reduce uncertainty in the design space.

Given the importance of uncertainty to design, it seems a likely candidate for exploration by design students who are establishing preliminary designer identities. Based on research with industrial design students, Tovey et al (2010) identify uncertainty as a "threshold concept" in design education - or one that holds the potential to open up a new pathway of understanding that may be otherwise elusive and is necessary for forward progress in the discipline. Threshold concepts are thought to support transformative learning at both the personal and conceptual levels, an experience that is indelible, integrative, and bothersome in a way that is motivating rather than limiting. For Tovey et al (2010), tolerance for design uncertainty as a threshold concept emerges "the moment when a student recognises that the uncertainty present when approaching a design brief is an essential, but at the same time routine, part of the design process" (p. 6). Once this threshold has been crossed, the path can then be opened for students to examine how they personally navigate the uncertain design space in service of their individual design 
practices and ways of being.

\subsection{What is it we are uncertain about?}

In order to better understand the role of uncertainty in design, it may be useful to momentarily move away from a generic definition of the term and consider more specifically what it is that we might be uncertain about in the design space. Within the design literature, the term uncertainty is typically broad and undifferentiated, although it been characterized more specifically as epistemic uncertainty, or participants' metacognition of their knowledge limitations, suggesting that designers are often aware of what it is that they know and do not know in the design space (Ball \& Christensen, 2009; Ball, Onarheim, \& Christensen, 2010). This type of uncertainty involves an element of probability, or the ability to estimate what it is known and unknown and as well as confidence in those estimates. Within the design space, uncertainty motivates designers toward resolution through action, and epistemic uncertainty has been identified as a mediator between design requirements and the deployment of particular design strategies (Ball, Onarheim, \& Christensen, 2010).

Epistemic uncertainty (or uncertainty about what we know) is only one type of uncertainty, however, When discussing how uncertainty relates to innovation within the context of economics, Lane \& Maxfield (2005) delineate three uncertain states: truth uncertainty (whether or not a proposition is true); semantic uncertainty (what a proposition means, particularly in relation to shared meaning among involved parties); and ontological uncertainty (lack of knowledge about relevant entities in a given situation, interactions among these entities, and resulting changes to both the entities and their interactivity as a consequence of said interactions). Both truth and semantic uncertainty represent aspects of epistemic uncertainty, which afford the subject with the ability to make predictions regarding accuracy, meaning, and 
confidence levels. Ontological uncertainty, or uncertainty about being or existence, involves a higher level of complexity than either truth or semantic uncertainty, as it is concerned with unknown entities and interactions that may emerge in the future after propositions are formed, often amidst rapidly changing situational factors. It also defies probabilistic estimations of the future, as we cannot make predictions about beings and relationships that we are not aware of in the first place.

At the same time, Lane \& Maxfield (2005) argue that ontological uncertainty is the condition most salient for innovation, which involves large-scale transformations of agents, artifacts, and/or the relationships between the two, with the possibility for transformation hinging on how individual actors manage ontological uncertainty. While the innovation process described by Lane \& Maxfield (2005) is not specifically aligned with or identified as design, it is clear that they overlap significantly, suggesting that it may be useful to consider how perceptions of epistemic uncertainty (the known unknowns, related to truth and meaning) and ontological uncertainty (the unknown unknowns, related to being and existence) may differentially influence designer responses and design outcomes.

A differentiated understanding of uncertainty is preliminary at best at this point, but we believe it will be fruitful to at least introduce a rudimentary typology as the basis for future discourse and research on uncertainty in design and design education. To briefly illustrate this model, we have pulled examples from an instructional design case and included them in Table 1. These examples are not meant to be exhaustive or definitive, but rather to illustrate how different types of uncertainty might emerge in a design problem.

[insert Table 1 about here] 


\subsection{Potential pathways of influence on designers and designerly ways of being}

Knowing that designers must spend a significant amount of time in a state of uncertainty (be it epistemic, ontological, or both), it seems fruitful to consider how uncertainty may exert an influence on how designers think, feel, and act when they are being designers. Although discourse on this topic in design is scarce, the psychological literature includes considerable research on individual cognitive, affective, and behavioral outcomes related to uncertainty. It is important to note that such research is often experimental in nature; aimed at the general population rather than professional design practitioners; and is frequently (although not exclusively) concerned with links between uncertainty and mental health. However, we believe these findings are useful for establishing exploratory notions about how uncertainty may shape designerly ways of being at the level of the individual professional.

While situational uncertainty in and of itself is associated with outcomes such as increased stress and intensified emotional reactions, regardless of the subject (Bar-Anan et al, 2009; Rosen et al 2014), individual traits - or relatively stable patterns of cognitive, behavioral, and affective responses - are associated with particular outcomes above and beyond what may be attributable to situational uncertainty. These attitudes and outcomes can be viewed from two perspectives: (1) how people respond given the opportunity to engage with uncertainty, or their uncertainty orientation, and (2) how they respond once they have entered an uncertain state, or their tolerance/intolerance for uncertainty.

\subsubsection{Responses to the uncertain state}

Uncertainty orientation (UO), a concept that emerged from social psychology, addresses an individual's willingness to engage when presented with an uncertain situation (Rosen et al, 
2014; Sorrentino, Smithson, Hodson, Roney, \& Walker, 2003). As defined by Sorrentino et al (2003), UO is a binary categorical approach that identifies whether or not an individual is motivated to engage with uncertain situations in order to resolve them, or motivated to favor situations that are familiar and preserving of existing clarity. In both cases, the uncertain state is regarded as aversive but, for those who are motivated to approach it, the rewards of gaining new knowledge outweigh the pains associated with entering uncertainty. UO has been associated with differences in information seeking and processing, decision-making, and motivation to achieve (Rosen et al, 2014; Sorrentino et al, 2003). This construct seems particularly relevant for understanding relationships between designers and uncertainty, and may provide insight into why some people are drawn to design professions.

\subsubsection{Responses within the uncertain state}

Rosen et al (2014) reviewed the psychological literature related to uncertainty and identified three separate but related constructs that address human responses once the uncertain state has been entered: intolerance of uncertainty (IU), intolerance of ambiguity (IA), and need for cognitive closure (NCC). IU and IA are dimensional measures of personality that describe the psychological effects of uncertain or ambiguous situations, which are triggered by underlying schema regarding the meaning and consequences of uncertainty and ambiguity. As a side note, ambiguity is a concept that is sometimes subsumed under the term uncertainty and sometimes addressed as a separate concept within psychological research, with uncertainty directed at the future and ambiguity located within the present moment (Bors, Gruman, \& Shukla, 2010; Kornilova \& Kornilov, 2010). Both uncertainty and ambiguity have been recognized as important to the design space (Cross, 2011; Eckert, Stacey, \& Earl, 2003), so research regarding both was included in this review. NCC describes the individual's desire to achieve closure in 
order to resolve situational uncertainty or to avoid closure and preserve ambiguity; as with IU and IA, this motivation is located along a continuum (Rosen et al, 2014). While these three constructs overlap, they also capture slightly different aspects of uncertainty-related cognition, affect, and behavior, and all may play an important role in understanding how individual designers interact with uncertainty in the design space.

Strong empirical findings link high IU (and high IA to a lesser extent) with affective, cognitive, and behavioral outcomes such as clinically-significant anxiety and depression, increased stress, maladaptive coping, lower quality of life, avoidance of novel situations, information processing and recall biases (favoring absolutists interpretations and recall of uncertainty-marked information), diminished behavioral performance, and impulsive decisionmaking (Birrell, Meares, Wilkinson, \& Freeston, 2011; Dugas et al, 2005; Erez \& Nouri, 2010; Kornilova \& Kornilov, 2010; Luhmann, Ishida, \& Hajcak, 2011; Rosen et al, 2014). Some studies have also shown that a high tolerance for uncertainty is associated with greater creativity (Kornilova \& Kornilov, 2010; Erez \& Nouri, 2010). Finally, high NCC has been related to impulsive decision-making and increased likelihood of anxiety and depression (Rosen et al, 2014).

Several key themes emerge from this overview:

1. Uncertainty is central to design and designers seek to reduce it via problemsolution co-evolution.

2. It can serve as a threshold concept in design education, allowing students access to new pathways of knowledge.

3. Current conceptions of uncertainty tend toward the generic, but there may be value in differentiating types of uncertainty. 
4. Uncertainty may influence cognition, behavior, and emotion depending on the psychological makeup of the individual.

We believe these themes lend strong support to the importance of including identitybuilding experiences related to uncertainty in design education. The next section outlines a rationale for incorporating reflective writing as a meaningful instructional strategy for supporting professional identity development.

\section{Professional identity, design education, and reflective writing}

As mentioned previously, professional identity is a dynamic understanding of our professional responsibilities, actions, beliefs, and values and how we embody our individual characteristics within this schema in the act of being a professional (Dall'Alba, 2009; Luehmann, 2007). Thus, understanding both the role of uncertainty in design and our individual attitudes toward uncertainty can be seen as important components of professional identity for designers. It is this link between what we know about uncertainty in general and how we experience personally it that allows us to embody our professional expertise and skills in ways that are intimate and idiosyncratic. Identity work is a common component of post-secondary education in a number of fields (including the medical and teaching professions), but is only beginning to be incorporated as a specific and intentional component of design education programs (Luehmann, 2007; Tovey et al, 2010; Tracey, Hutchinson, \& Grzebyk, 2014).

Schön's (1983) work on reflection in in the professional sphere provides a useful format for considering and re-considering beliefs, experiences, and the self in service of professional identity construction. Within this framework, reflection can be aimed at different chronological points: reflection-in-action focuses on what is occurring in the moment; reflection-on-action addresses what has happened in the past; and reflection-for-action is directed at what might 
happen in the future. For design students, the latter approach might be particularly useful in identity construction, as it provides room to consider what might be and who they might become as their professional practice matures, in light of what they currently understand about design and about themselves. Incorporating exercises in reflection in design education provides a dual benefit: not only are students using reflection to build a sense of themselves as designers, but they are doing so by engaging in a designerly way of being, as reflective conversations with the design problem are characteristic of how designers practice (Cross, 2011; Nelson \& Stolterman, 2012).

Reflection is a narrative process at its core, and reflective writing is a common pedagogical approach used in identity development as it gives students the space to explore the stories they tell themselves about themselves, their experiences, and their beliefs (Bourner, 2003; Davis, 2006; Henderson, Napan, \& Montiero, 2004; Luehmann, 2007). There is also an empirical basis for using reflective writing as a learning activity to engage students in belief examination and change resulting from the integration of personal experiences into a framework of professional knowledge and/or identity (Tracey \& Hutchinson, 2013; Tillema, 2000). Reflective writing as an instructional approach dates back to the work of Dewey (1933), who advocated for the use of unguided writing that placed agency over content and structure in the hands of the student. However, contemporary research suggests that students, particularly when they are novices in a field, may benefit from scaffolding to guide the reflective process, including prompts that encourage them to draw connections between course content and personal experiences (Whipp, 2003). At the same time, it is crucial to align scaffolding with student development in order to ensure that prompts or other structuring activities continually push students to achieve greater complexity as their knowledge base grows and their reflective 
abilities mature (Ada, 2010).

\section{Methodology}

\subsection{Research context and questions}

This research project emerged from a larger, long-term investigation of reflective writing and identity development in design education (see Tracey \& Hutchinson, in revision, for more details). Our master data set includes student responses to nine prompts that cover beliefs about design, design-related experiences, and awareness of the self-as-designer. We chose to address prompts related to uncertainty independent of the other data primarily because the issue is complex and compelling, as outlined above in Section 2. Given the sheer size of our data set (with over 3,756 total coding decisions), it was simply not feasible to give adequate and meaningful attention to the topic at hand within a broad overview of the research.

Our specific research questions regarding uncertainty include:

1. Do students engage in reflection in narratives on uncertainty and if so, what aspects of reflection do students include in their writing? The second question is particularly important as a binary approach to reflection (i.e., judging something as reflective or not) does little to tell us about the nature of student writing and how reflection is being manifested in their work.

2. Do student attitudes toward uncertainty change over the course of a semester, and if so, how? Understanding how reflection can support belief change is particularly important for identity work, which can involve a great deal of mutability, particularly when identities are initially being established (Luehmann, 2007).

\subsection{Participants and instructional context}

Participants included a total of 69 students enrolled in four consecutive semesters of an 
introductory instructional design (ID) course offered online by an urban university in the Midwestern United States. Although instructional design has historically been a processoriented field, there has been a recent shift toward alignment with the larger design community by some in the field (Tracey \& Boling, 2013). ID shares many commonalities with other design disciplines, with a focus on solving the wicked problems of human learning. Designing an educational program for a healthcare system for example may require designing instruction for multiple audiences including physicians, patients, support staff, healthcare external suppliers and healthcare system administrators while adhering to time, budget and resource constraints. The final educational products may need to be compatible with multiple delivery systems and offered in several different languages. In this example, instructional designers similar to designers in the larger design community embrace the attitudes of design thinking while drawing on creativity, intuition and expertise.

The course included in this study uses design thinking rather than traditional ID process models to drive the curriculum, devoting the first seven weeks to general design principles based primarily on Cross (2011) which is a required text, then integrating ID-specific concepts and content into this framework for the remaining weeks of the term. Class activities are constructivist in nature, including reflective writing, case studies, peer group interaction, and an individual project addressing an ill-structured ID problem.

This class is required of all graduate students entering either the master's or doctoral program in this university's instructional technology program (which encompasses performance systems and technology integration as well as instructional design). It is important to recognize that students in this course do not typically enter the program with an awareness of design thinking or an understanding that instructional design can be viewed as congruent with other 
design disciplines. Among those that do have a reasonably formed opinion of the field, a modeldriven view of instructional design dominates. In addition, because the course is also a requirement for a graduate certificate in online teaching that is offered to students from all departments in the university, some entering students know little to nothing about the field or about design. The academic background of participants is quite varied as a consequence; to name a few, library science, audiology, music education, business administration, and educational psychology have all been represented in recent years. Taken together, very few students enter the course either identifying as a designer or expecting to cultivate such an identity. This may set ID education apart from some other design fields, whose students enter eager to assume the role of designer.

Another distinctive feature of instructional design as compared to many other design disciplines is a heavy emphasis on writing as part of professional practice. Instructional designers write a great deal, with outputs ranging from detailed design specifications to instructional materials to scripts for facilitators. However, this writing is typically objective in nature and even when it does veer into subjective territory (for example, a facilitator script ideally sounds like a person speaking naturally), it is not from the point of view of the designer but rather some other stakeholder in the process. So, while instructional design courses tend to include a great deal of written work, the subjective and intimate nature of reflective writing is quite different from the professional writing style that is typically taught in ID courses, and thus introduced an element of uncertainty into students' experience of the class.

\subsection{Data sources and collection}

Data sources included online reflection journals that students maintained throughout the semester as a course requirement. Journal entries written in response to prompts provided by the 
instructor were required during eight weeks of the 14-week semester. Students created their journals in Google Documents with access granted to the instructor for review, formative feedback, and summative assessment. Twice during the semester, students were asked to reflect on their experiences and attitudes toward uncertainty: once in the first week of class, and again in the fifth week. The text of the prompts was as follows:

Prompt 1.3 (the third prompt in the first week of the course): "Describe a time when you felt totally uncertain. Try to remember how that felt and the greatest challenges you faced because of the uncertainty. What did you do to handle it? Knowing that part of being a designer is always dealing with uncertainty, how do you feel about being a designer?"

Prompt 5.5 (the fifth prompt in the fifth week of the class): "What are your thoughts about the last slide in the PPT presentation this week? Please share where you are today." (The slide referred to in the prompt emphasized the role of uncertainty in design).

From an instructional perspective, the prompts were structured and sequenced to introduce participants to the topic of uncertainty by first describing a general experience from any aspect of their life. Then, later in the semester, they were asked to directly confront the integration of uncertainty, design, and self after gaining more experience with the design thinking approach and a greater understanding of what it means to be a designer, a more challenging and complex topic. The prompts also intentionally differ in the amount of structure they provided; the first prompt was worded to provide a great deal of support to students in terms of what they could or should address in their response, while the second prompt faded this structure in order to challenge students to take greater ownership of their writing and its form.

At the end of each semester, students were invited to participate in the study and the instructor then forwarded the journals of those students who gave consent to the research team 
(after removing any identifying information). The lead data coder, a doctoral student in ID, performed a second review to ensure subject anonymity, then created separate documents that organized student responses by prompt and semester to be used by data coders. Although 69 students agreed to participate in this study, subject counts for each prompt are slightly lower because not every student provided an answer for each prompt in their reflection journal. For Prompt 1.3, 67 participants provided responses and 68 provided a response for Prompt 5.5, for a total $\mathrm{N}=135$ responses.

\subsection{Data Assessment}

The REFLECT rubric (Wald, Borkan, Taylor, Anthony, \& Reis, 2012), a model for assessing reflective writing, was used to code each response. The rubric allows for four levels of reflection, listed below with a general characterization:

- Habitual action, which remains at the level of basic fact reporting and typically omits major elements of the response.

- Thoughtful action, which includes a more elaborate or detailed narrative but remains at the descriptive level.

- Reflection, which involves an effort to engage in meaning-making, analysis, or some other aspect of reflection.

- Critical reflection, which results in a comprehensive response that considers multiple interpretations or viewpoints.

REFLECT moves beyond a binary approach to reflection (i.e., whether something is or is not reflection) and instead provides six criteria that represent different aspects of reflection, defined as follows:

- Writing spectrum, or the overall reflective quality of the writing. 
- Presence, or the sense of the writer's presence in the response.

- Conflict description, or the recounting of the precipitating conflict or situation.

- Emotion, or recognition and attention to emotional aspects of the situation.

- Analysis, or effort directed toward meaning-making or analysis of the situation.

- Attention to assignment, or responsiveness to the prompt.

REFLECT was selected for this research specifically because it provides for a much more nuanced understanding of how students are engaging in reflection and if there are aspects of reflection that are being privileged or neglected in their writing. Exploring this complexity was integral to the project's first research question, and among available rubrics uncovered in a literature search, REFLECT stood apart for addressing multiple aspects of reflection, for providing multiple levels of reflection, and for sound inter-rater reliability rates (Wald et al, 2012). See Table 2 for the full REFLECT rubric, including coding guidelines specific to each of the six reflection criteria. Previous research by the authors has demonstrated the utility and reliability of the REFLECT rubric for assessing reflection in graduate design education (Tracey, Hutchinson, and Gryzbek, 2014).

[insert Table 2 about here]

In addition to the REFLECT rubric, responses were coded for orientation toward uncertainty in general alignment with the UO construct identified earlier. We felt this was the most applicable for the data we would be collecting, as it addressed uncertainty by looking at the motivation to engage (or not) with uncertain situations. However, the binary approach of UO as defined by Sorrentino et al (2003), where participants either embrace or avoid uncertainty, did 
not adequately capture the nature of our participants responses, as many indicated mixed attitudes or did not clearly account for their own orientation. Final uncertainty orientation categories for the study included: positive (overall positive attitude signaling an embracing of uncertainty); negative (overall negative attitude signaling avoidance of uncertainty); mixed (attitude specifically incorporating positive and negative aspects); and unclear or not indicated (response either does not address uncertainty orientation or is unclear in some way).

Each individual response $(\mathrm{N}=135)$ was assessed by at least two data coders using the REFLECT rubric and the uncertainty orientation criteria (for a total of seven coding decisions per response, or 945 total decisions for the data set). If the two initial coders agreed on a particular coding decision, the assessment was considered final. If they disagreed, a third reviewer coded the response. If three coders disagreed, then the coding decision was sent to the principal researchers for final adjudication.

\section{Results}

Table 3 details coding results by reflection criteria, prompt, and semester. Of the 810 decisions relating to the REFLECT rubric, 97\% achieved consensus from two out of three reviewers, with the remaining 3\% sent to the PIs for final adjudication. For the 135 decisions relating to uncertainty orientation, $93 \%$ achieved agreement among two of three reviewers, with $7 \%$ referred for final adjudication.

[insert Table 3 about here]

\subsection{Aggregated reflection levels}

It is important to initially consider aggregated reflection levels for both prompts across all six domains of the REFLECT rubric as this provides a general context for better understanding congruencies and deviations. As Figure 1 shows, $58 \%$ of all coding decisions fell into the 
reflection category, followed by $33 \%$ as thoughtful action, $6 \%$ as habitual action, and $3 \%$ as critical reflection. As a point of comparison, results from our larger data set (which included nine prompts and 3,756 coding decisions) were $49 \%$ reflection, $37 \%$ thoughtful action, $12 \%$ habitual action, and $2 \%$ critical reflection.

[insert Figure 1 about here]

\subsection{Reflection levels by REFLECT criteria}

Aggregated reflection levels for each of the six REFLECT criteria are also included in Figure 1. The Presence dimension saw the highest level of reflection at $89 \%$, while Emotion generated the lowest levels, with reflection at $33 \%$ and critical reflection at $1 \%$. In line with this, Presence had the lowest levels of thoughtful and habitual action (10\% and $1 \%$ respectively), while Emotion had the highest levels at $18 \%$ habitual action and $48 \%$ thoughtful action. The remaining four criteria had similar results for reflection, with all four at either $55 \%$ or $56 \%$; however, Writing spectrum and Analysis had the overall highest levels of critical reflection, at $9 \%$ and $7 \%$ respectively. In terms of thoughtful action, Conflict and Attention to Assignment had the highest rates of the remaining criteria, and were followed by Analysis and Writing Spectrum. Finally, among the remaining criteria, Writing Spectrum had the highest level of habitual action, followed by Assignment, Conflict, and Analysis.

[insert Figure 1 about here]

\subsection{Between-prompt differences}

Figure 2 illustrates the differences in reflection levels between Prompt 1.3 and Prompt 5.5. For Prompt 1.3, $68 \%$ of all decisions were coded as reflection, followed by $24 \%$ as thoughtful action, $5 \%$ as habitual action, and 3\% as critical reflection. For Prompt 5.5, 46\% of all 
decisions were coded as reflection, $44 \%$ as thoughtful action, $6 \%$ as habitual action, and $4 \%$ as critical reflection.

In terms of changes within reflection qualities, all dimensions saw a shift toward less reflection and more descriptive action from Prompt 1.3 to Prompt 5.5, except for presence, which held relatively steady (90\% reflection for Prompt 1 compared to $88 \%$ for Prompt 2 ). Attention to assignment and emotion generated the biggest changes, with attention to assignment seeing a drop from $71 \%$ to $42 \%$, while emotion fell from $50 \%$ (reflection and critical reflection) to $16 \%$. These were followed by analysis (a drop of 24\%), conflict (a drop of 24\%), and writing spectrum (a drop of 9\%). See Figure 2 for more detail.

[insert Figure 2 about here]

\subsection{Uncertainty orientation}

Our second research question concerned whether and how participants may reconsider their uncertainty orientation across the semester. A comparison of results for Prompts 1.3 and 5.5 shows an increase in positive orientation from $44 \%$ to $54 \%$; a negligible increase in mixed orientation from $24 \%$ to $25 \%$; a decrease in negative orientation from $9 \%$ to $3 \%$; and a decrease in not indicated/unclear orientation from $24 \%$ to $18 \%$ (see Figure 3 ).

[insert Figure 3 about here]

\section{Discussion}

It is clear from the results that participants were generally able to engage in reflection when responding to prompts regarding uncertainty (with $61 \%$ of coding decisions achieving either reflection or critical reflection). At the same time, there were aspects of reflection students were more comfortable incorporating in their narratives, and others that appeared to be more 
challenging. Presence was the most reflective criterion at $89 \%$, which suggests participants are at ease including their own voice and perspective when discussing uncertainty. Interestingly, in our larger data set (covering nine prompts in total), aggregated reflection rates for presence only reached $79 \%$, so participants may have been more comfortable establishing their authorial presence when discussing uncertainty versus other topics. Writing spectrum (64\%) and analysis $(63 \%)$ had the next highest levels of reflection, indicating that participants were able to use the writing process to make meaning from their experiences most of the time. Emotion was the least reflective criterion overall, with only $34 \%$ of aggregated responses coded as either reflection or critical reflection. This is consistent with our previous research; however, within our larger data set, the emotion criterion was even less reflective with only $15 \%$ coded as reflection or critical reflection.

When considered against our larger data set of nine prompts, Prompt 1.3 had the highest overall rate of reflection (71\% reflection and critical reflection) and the highest or second highest reflection level for all six REFLECT criteria. This suggests that students were able to engage with this prompt relatively easily and make meaning from their general experiences with uncertainty. However, when students revisited the topic of uncertainty for Prompt 5.5 (which asked them to assess themselves in relation to uncertainty in design), reflection levels fell to $51 \%$ reflection and critical reflection. This regression was not unexpected and can be considered indicative of the recursive, dynamic nature of identity development, particularly when confronted with a complex challenge that requires (re)consideration and (re)integration of the self within the professional context. For Prompt 1.3, students had the freedom to choose an experience with uncertainty from any point in their history, which allowed them to grant themselves chronological, cognitive, and emotional distance from the event if they chose to do so. 
For Prompt 5.5, students had to discuss their current position and sense of self in relation to uncertainty in design, which may not have been fully processed at the time and thus more difficult for students to reflect on productively. Likewise, course content during the intervening weeks may have complicated participants' understanding of design, uncertainty, and/or the relationship between the two, which again may have constrained their ability to reflect in the present moment. At the same time, those who were able to reflect in relation to the Writing Spectrum criterion for Prompt 5.5 achieved critical reflection at twice the rate of Prompt 1.3 $(12 \%$ vs. $6 \%)$.

An interesting difference in the results comes from reflection in relation to the emotion criterion: $51 \%$ reflection and critical reflection for Prompt 1.3 and only $16 \%$ for Prompt 5.5. This may be attributable to the wording of Prompt 1.3, which specifically asked students to describe how they felt during an uncertain situation. It is interesting to note, though, that students still struggled to incorporate affective components in their responses to Prompt 1.3, with only $50 \%$ attending to emotions or gaining emotional insight, despite direct guidance to consider their feelings in their response. Overall, these findings suggest that these students struggled to reflect on emotions in relation to design, despite its importance to the field and even when they were engaging in other aspects of reflection.

It also bears mention that only $42 \%$ of responses for Prompt 5.5 were coded as reflection for the Attention to Assignment criterion (compared to 71\% for Prompt 1.3), which means that $58 \%$ did not fully address the prompt or give a compelling reason for an alternate response. Because the prompt itself is short and direct, these results add further support to the idea that students found the integration of self and design to be challenging.

Overall, three-quarters of students either had a positive (49\%) or mixed $(24 \%)$ 
uncertainty orientation. Participants also demonstrated increased positive orientation rates from Prompt 1.3 (67\% positive or mixed) to Prompt 5.5 (79\% positive or mixed). These findings address our second research question and indicate that reflective writing may help students clarify and/or transform their own uncertainty orientations. While these results seem encouraging on the surface, it is possible that this reflects an unconscious bias to align one's self with perceived qualities of what makes a good designer rather than an objective self-assessment. Since the course content emphasizes the role of uncertainty in design, students who aspire to become designers may adopt the orientation they think they should have. Positive associations with uncertainty may also reflect a naïve understanding of the realities of dealing with unpredictable, messy design problems, while a mixed orientation is able to incorporate both positive and negative aspects in a realistic way. Finally, one in five responses failed to include a clear orientation toward uncertainty, despite the fact that both prompts directly asked them to do so. This suggests that certain students find it challenging to identify how they feel about uncertainty, let alone analyze it.

\subsection{Implications for design education and professional identity development}

The overarching instructional goal of the reflection journal assignments was to introduce students to important concepts and experiences related to design, as well as provide them with opportunities to integrate their own personal qualities and histories with their emerging schema about design and designers as identity-building work. The results support the use of reflective writing as an effective tool for exploring identity-related issues in graduate design education, with the knowledge that students' ideas about design and self-as-designer will evolve with time and experience. What is most important is to give them exposure to important concepts and experiences they will encounter in their professional practice, as well as practice using reflection 
to process and analyze these experiences and transform them into design precedents. Particularly for students who may be unfamiliar or uncomfortable with reflective writing, multiple opportunities to engage in the activity coupled with timely and personal feedback will be important to build confidence in their abilities. While we certainly encourage the use of reflective writing in particular, other modes of expression might be equally applicable and allow students the added opportunity to practice using professional skills for subjective narrations related to professional identity. For example, architecture students could apply drafting skills to draw a visual representation of how they feel about uncertainty, or industrial design students could build a three-dimensional representation. Both would require students to reflect on experiences and translate their meaning into an external, socially-situated artifact of who they are or want to be while using professional skills in a novel application.

Without building direct experiences with uncertainty into the course content, however, it will likely be difficult for students to gain insight regarding design uncertainty and their designer selves, no matter how much reflecting they do. Engaging students in an authentic design problem from their field, through case studies or hands-on projects, is a logical way to introduce them to such uncertainty. In the class that was included in this study, one instructor asked each student to come up with an instructional design problem for their final project, with the constraints that it should involve adults and take no longer than an hour to deliver the instruction. Then she induced tremendous uncertainty by announcing the next week that they would all be switching problems with another student, acting as the client for the student who received their problem, and the designer for the student whose problem they received. This exercise, however frustrating at first, not only gave students the chance to work through uncertainty but also to build design knowledge and empathy by playing the role of client as well as designer. 
In terms of instructional practices, the REFLECT rubric provides important feedback on aspects of student reflection that may need additional support, such as emotion. Based on our findings, students in the course could have clearly benefited from significant scaffolding and feedback to better incorporate affective aspects into their reflection. Since empathy with the user is a core aspect of design (Rapanta \& Cantoni, 2014), emotional awareness and maturity seem particularly crucial to nurture and cultivate in design education in order to equip designers to connect with users; research findings support that designer empathy can have an influence on design outcomes (Kouprie \& Visser, 2009; Rapanta \& Cantoni, 2014). Empathy itself is not an emotion, but rather the ability to understand another's emotional state (Sas \& Zhang, 2010); however, the ability to develop empathetic skills may rest in the ability to understand one's own emotions. Furthermore, designers' emotions and emotional processing in the design space unrelated to empathy - have been found to influence design actions and outcomes (Davis, 2009; DeDru, Baas \& Nijstad, 2008; Yang \& Hung, 2014), which is not surprising, given the relationships that exist between and among uncertainty and cognition, emotion, and behavior. There are other findings that point to the value of designer emotions as a feedback mechanism, although as with other research on the affective experiences of designers, this work is preliminary (Alexiou, Zamenopoulos, Johnson, \& Gilbert, 2009 Dong, Kleinsmann, \& Valkenburg, 2008; Kim, Bouchard, \& Ryu, 2012). Finally, the development of professional identity in any field - and education in general - hinges on understanding and transforming the self and cannot be separated from our emotional experience of who we are in any given context (Heidegger, 1967).

Since this study is part of a larger, design-based inquiry into professional identity and design education, these results will be used to review instructional activities and make 
adjustments as needed. Based on preliminary findings, we have previously edited or eliminated prompts that did not seem to provide valuable learning experiences to our students. We are currently planning a major redesign of the course and, given these findings, we will revisit the wording of Prompt 5.5 to see if modifications might be useful to support students in generating reflection in relation to uncertainty.

\subsection{Implications for design research}

Given the instructional context of this research, it was necessary to take a general approach to the idea of uncertainty to best serve the learners, rather than focusing on a specific type of uncertainty (such as ontological or epistemic). However, we believe it is vitally important to investigate if and how different forms of uncertainty affect the design space, design actions, and design outcomes. Lane \& Maxfield (2005) make a powerful case for the connection between ontological uncertainty and innovation, supplemented by a provocative narrative theory of action to explain how individuals manage and use the condition of ontological uncertainty to foster innovation. Most design research, however, does not delineate what is meant by uncertainty beyond the general, day-to-day meaning of the word. Understanding how different forms of knowledge deficits operate and exert influence could provide significant insights into design and design thinking.

Along these lines, it is equally important to investigate how individual responses to uncertainty may influence design actions and outcomes. The psychological literature has identified clear associations between individual attitudes toward uncertainty (both affective and cognitive) and a range of behavioral, emotional, and cognitive outcomes. It would logically follow that individual designer's attitude toward uncertainty may differentially affect the design process, but the research literature has been largely silent on this issue until now. Any of the 
four uncertainty constructs discussed earlier (UO, IU, IA, and NCC) may be useful in understanding how individual responses to uncertainty are expressed in the design space as well as the implications of these response patterns in terms for design outcomes. Because designers serve as the arbiters of the design space, we will not fully understand the act of designing without understanding how the psychological makeup of individual designers influences their design actions and decisions.

The REFLECT rubric was useful for establishing the validity of reflective writing in design education and for delineating aspects of reflection that are more or less prominent in participants' writing. Going forward, however, content analysis of student responses to uncertainty prompts may generate additional insights into how emerging designers manage this aspect of the design space. For example, it will be important to understand what aspects of uncertainty they identify as positive or negative and what strategies they have in place to manage uncertainty. Content analysis may also shed light on what forms of uncertainty are most prominent in designers' perceptions of and reflections on design.

Finally, more scholarly attention needs to be paid to the development and maintenance of professional identity in designers, both novice and expert. Given the influence designers have over design outcomes and the responsibilities they hold in the design space, it is crucial for individual designers to be able to understand, articulate, and reflect on themselves, their profession, and the integration of the two. It will be important to explore these issues in different disciplines and educational contexts, as well as investigate institutional and/or cultural barriers that may make it challenging for design educators to incorporate reflective experiences. Adams, Daly, Mann, \& Dall'Alba, (2011) use the framework of knowing, acting, and being to explore how designers articulate and understand their professional responsibilities; this an important 
contribution to our preliminary understanding of designer identity and more work like this would enrich current discourse on the topic.

This research study provides an important framework for understanding the intersection of uncertainty, design, and professional identity development. Uncertainty in the design space is a subject ripe for deeper exploration, as is the role of individual designers' attitudes toward uncertainty. Likewise, we hope that this research spurs further discourse on how designers construct and refine professional identity, and how design education programs can support this process. 


\section{References}

Ada, W.W. (2010). Computer supported collaborative learning and critical reflection: A case study of fashion consumerism. Interdisciplinary Journal of E-Learning and Learning Objects, 6, 87-102.

Adams, R. S., Daly, S. R., Mann, L. M., \& Dall'Alba, G. (2011). Being a professional: Three lenses into design thinking, acting, and being. Design Studies, 32(6), 588-607.

Alexiou, K., Zamenopoulos, T., Johnson, J. H., \& Gilbert, S. J. (2009). Exploring the neurological basis of design cognition using brain imaging: some preliminary results. Design Studies, 30(6), 623-647.

Ball, L. J., \& Christensen, B. T. (2009). Analogical reasoning and mental simulation in design: two strategies linked to uncertainty resolution. Design Studies, 30(2), 169-186.

Ball, L. J., Onarheim, B., \& Christensen, B. T. (2010). Design requirements, epistemic uncertainty and solution development strategies in software design. Design Studies, $31(6), 567-589$.

Bar-Anan, Y., Wilson, T. D., \& Gilbert, D. T. (2009). The feeling of uncertainty intensifies affective reactions. Emotion, 9(1), 123.

Birrell, J., Meares, K., Wilkinson, A., \& Freeston, M. (2011). Toward a definition of intolerance of uncertainty: A review of factor analytical studies of the Intolerance of Uncertainty Scale. Clinical Psychology Review, 31(7), 1198-1208.

Bors, D. A., Gruman, J. A., \& Shukla, S. (2010). Measuring tolerance of ambiguity: Item polarity, dimensionality, and criterion validity. Revue Européenne de Psychologie Appliquée/European Review of Applied Psychology, 60(4), 239-245. 
Bourner, T. (2003) Assessing reflective learning. Education + Training, 45, 267-272.

Buchanan, R. (1992). Wicked problems in design thinking. Design Issues, 8(2), 5-21.

Dall'Alba, G. (2009). Learning professional ways of being: Ambiguities of becoming. Educational Philosophy and Theory, 41(1), 34-45. doi10.1111/j.1469-5812.00475.x.

Davis, E.A. (2006). Characterizing productive reflection among preservice elementary teachers: Seeing what matters. Teaching and Teacher Education, 22, 281-301. doi: 10.1016/j.tate.2005.11.005.

Dewey, J. (1933). How we think: A restatement of the relation of reflective thinking to the educative process. Boston: DC Heath.

Dong, A., Kleinsmann, M., \& Valkenburg, R. (2009). Affect-in-cognition through the language of appraisals. Design Studies, 30(2), 138-153. doi: 10.1016/j.destud.2008.12.003

Dorst, K., \& Cross, N. (2001). Creativity in the design process: co-evolution of problemsolution. Design Studies, 22(5), 425-437.

Dugas, M. J., Hedayati, M., Karavidas, A., Buhr, K., Francis, K., \& Phillips, N. A. (2005). Intolerance of uncertainty and information processing: Evidence of biased recall and interpretations. Cognitive Therapy and Research, 29(1), 57-70.

Eckert, C., Stacey, M., \& Earl, C. (2003). Ambiguity is a double-edged sword: Similarity references in communication. Proceedings of the 14th International Conference on Engineering Design.

Erez, M., \& Nouri, R. (2010). Creativity: The influence of cultural, social, and work contexts. Management and Organization Review, 6(3), 351-370.

Heidegger, M. (1962). Being and time. New York, NY: Harper \& Row, Publishers, Incorporated. 
Henderson, K., Napan, K., \& Monteiro, S. (2004). Encouraging reflective learning: An online challenge. In Beyond the comfort zone: Proceedings of the 21st ASCILITE Conference (pp. 357-364).

Kacin, S. E. (2013). A design-based research study examining the impact of motivational emailed messages to first year students. Wayne State University Dissertations. Paper 664, http://digitalcommons.wayne.edu/oa_dissertations/664.

Kim, J., Bouchard, C., and Ryu, H. (2012). Emotion finds a way to users from designers: assessing product images to convey designer's emotion. Journal of Design Research, $10(4), 307-323$.

Kornilova, T. V., \& Kornilov, S. A. (2010). Intelligence and tolerance/intolerance for uncertainty as predictors of creativity. Psychology in Russia: State of the Art, 3, 240-256.

Kouprie, M., \& Visser, F. S. (2009). A framework for empathy in design: stepping into and out of the user's life. Journal of Engineering Design, 20(5), 437-448.

Lane, D. A., \& Maxfield, R. R. (2005). Ontological uncertainty and innovation. Journal of Evolutionary Economics, 15(1), 3-50.

Luehmann, A.L. (2007). Identity development as a lens to science teacher preparation. Science Education, 91, 822-839. doi: 10.1002/sce20209.

Luhmann, C. C., Ishida, K., \& Hajcak, G. (2011). Intolerance of uncertainty and decisions about delayed, probabilistic rewards. Behavior Therapy, 42(3), 378-386.

Nelson, H.G., \& Stolterman, E. (2012). The design way: Intentional change in an unpredictable world $\left(2^{\text {nd }}\right.$ ed. $)$ Cambridge, MA: MIT Press. 
Rapanta, C. \& Cantoni, L. (2014). Being in the users' shoes: Anticipating experience while designing online courses. British Journal of Educational Technology, 45(5), 765-777. doi:10.1111/bjet.12102

Rosen, N. O., Ivanova, E., \& Knäuper, B. (2014). Differentiating intolerance of uncertainty from three related but distinct constructs. Anxiety, Stress \& Coping, 27(1), 55-73.

Sas, C., \& Zhang, C. (2010). Do emotions matter in creative design?. In Proceedings of the 8th ACM Conference on Designing Interactive Systems (pp. 372-375). ACM.

Schön, D. (1983). The Reflective Practitioner: How professionals think in action. New York: Basic Books Inc.

Solovyova, I. (2003). Conjecture and emotion: An investigation of the relationship between design thinking and emotional content. In Expertise in design: Design thinking research symposium (Vol. 6).

Sorrentino, R. M., Smithson, M., Hodson, G., Roney, C. J., \& Marie Walker, A. (2003). The theory of uncertainty orientation: A mathematical reformulation. Journal of Mathematical Psychology, 47(2), 132-149.

Tillema, H. H. (2000). Belief change towards self-directed learning in student teachers: immersion in practice or reflection on action. Teaching and Teacher Education, 16, 575591. doi:10.1016/S0742-051X(00)00016-0.

Tovey, M., Bull, K., \& Osmond, J. (2010). Developing a pedagogic framework for product and automotive design. In 2010 Design Research Society (DRS) International Conference on Design \& Complexity.

Tracey, M.W., \& Boling, E. (2013). Preparing instructional designers and educational technologists: Traditional and emerging perspectives. In M. Spector, D. Merrill, J. Elen, 
\& M.J. Bishop (Eds.), Handbook of Research on Educational Communications and Technology (4 ${ }^{\text {th }}$ ed.). (pp.653-660). New York: Springer.

Tracey, M.W., \& Hutchinson, A. (2013). Developing designer identity through reflection. Educational Technology, 53(3), 28-32.

Tracey, M.W., \& Hutchinson, A. (in revision). Reflection, professional identity, and instructional design education.

Tracey, M.W., Hutchinson, A., \& Grzebyk, T. (2014). Instructional designers as reflective practitioners: Developing professional identity through reflection. Educational Technology Research \& Development.

Wald, H. S., Borkan, J. M., Taylor, J. S., Anthony, D., \& Reis, S. P. (2012). Fostering and evaluating reflective capacity in medical education: Developing the REFLECT rubric for assessing reflective writing. Academic Medicine, 87, 41-50.

Whipp, J. (2003). Scaffolding critical reflection in online discussions: Helping prospective teachers think deeply about field experiences in urban schools. Journal of Teacher Education, 54, 321-34. doi:10.1177/0022487103255010. 


\section{Table 1: Examples of epistemic and ontological uncertainty in design}

Case Study: With the goal of improving undergraduate student retention, an instructional designer designed and sent strategically delivered motivational emails to first year students over a fifteen-week period during one semester (Kacin, 2013).

\begin{tabular}{|l|l|}
\hline Type of uncertainty & Examples of Uncertainty in the Design Case \\
\hline Epistemic related to truth & $\begin{array}{l}\text { What are the retention rates? Does motivation correlate with } \\
\text { retention? What points in the semester involve the highest dropout } \\
\text { rates? What other programs or resources are in place to promote } \\
\text { retention among first-year undergraduates? }\end{array}$ \\
\hline $\begin{array}{l}\text { Epistemic related to } \\
\text { meaning }\end{array}$ & $\begin{array}{l}\text { How do undergraduate students respond to email? Will } \\
\text { undergraduate students respond to motivational emails sent from } \\
\text { someone other than the instructor? What types of messages do } \\
\text { undergraduates find motivating? How is motivation addressed in } \\
\text { other aspects of the students' courses? }\end{array}$ \\
\hline $\begin{array}{l}\text { Ontological related to being } \\
\text { and existence }\end{array}$ & $\begin{array}{l}\text { What are the contextual complexities inherent in undergraduate } \\
\text { students? How are undergraduate students motivated? What other } \\
\text { communication channels might emerge that could be effective in } \\
\text { reaching students? How might other interactions with instructors } \\
\text { outside of the designer's awareness support or limit the impact of the } \\
\text { motivational emails? }\end{array}$ \\
\hline
\end{tabular}


Table 2: Reflective assessments by semester and prompts

\begin{tabular}{|c|c|c|c|c|c|c|c|c|c|c|c|c|}
\hline & & \multicolumn{5}{|c|}{ Prompt 1} & \multicolumn{5}{|c|}{ Prompt 2} & \multirow[b]{2}{*}{135} \\
\hline & $\mathbf{N}$ & 17 & 20 & 11 & 20 & 68 & 17 & 21 & 10 & 19 & 67 & \\
\hline CRITERION & LEVEL & S1 & S2 & S3 & S4 & All & S1 & S2 & S3 & S4 & All & TOTAL \\
\hline Writing & HA & 0 & 1 & 1 & 3 & 5 & 2 & 1 & 0 & 1 & 4 & 9 \\
\hline \multirow[t]{3}{*}{ Spectrum } & TA & 2 & 7 & 3 & 4 & 16 & 7 & 9 & 1 & 6 & 23 & 39 \\
\hline & $\mathbf{R}$ & 11 & 12 & 7 & 13 & 43 & 7 & 9 & 7 & 9 & 32 & 75 \\
\hline & CR & 4 & 0 & 0 & 0 & 4 & 1 & 2 & 2 & 3 & 8 & 12 \\
\hline \multirow[t]{4}{*}{ Presence } & $H A^{1}$ & $n / a$ & 0 & 0 & 0 & 0 & $\mathrm{n} / \mathrm{a}$ & 1 & 0 & 0 & 1 & 1 \\
\hline & TA & 4 & 1 & 0 & 2 & 7 & 1 & 2 & 1 & 3 & 7 & 14 \\
\hline & $\mathbf{R}$ & 13 & 19 & 11 & 18 & 61 & 16 & 18 & 9 & 16 & 59 & 120 \\
\hline & $\mathrm{CR}^{2}$ & $\mathrm{n} / \mathrm{a}$ & $\mathrm{n} / \mathrm{a}$ & $\mathrm{n} / \mathrm{a}$ & $\mathrm{n} / \mathrm{a}$ & $n / a$ & $\mathrm{n} / \mathrm{a}$ & $\mathrm{n} / \mathrm{a}$ & $\mathrm{n} / \mathrm{a}$ & $\mathrm{n} / \mathrm{a}$ & $n / a$ & $\mathrm{n} / \mathrm{a}$ \\
\hline \multirow[t]{4}{*}{ Conflict } & HA & 1 & 1 & 0 & 0 & 2 & 1 & 0 & 0 & 1 & 2 & 4 \\
\hline & TA & 6 & 4 & 2 & 6 & 18 & 8 & 12 & 3 & 11 & 34 & 52 \\
\hline & $\mathbf{R}$ & 10 & 15 & 9 & 13 & 47 & 8 & 8 & 6 & 6 & 28 & 75 \\
\hline & CR & 0 & 0 & 0 & 1 & 1 & 0 & 1 & 1 & 1 & 3 & 4 \\
\hline \multirow[t]{4}{*}{ Emotion } & HA & 1 & 2 & 3 & 3 & 9 & 2 & 5 & 5 & 4 & 16 & 25 \\
\hline & TA & 2 & 11 & 5 & 7 & 25 & 11 & 14 & 2 & 13 & 40 & 65 \\
\hline & $\mathbf{R}$ & 14 & 6 & 3 & 10 & 33 & 4 & 2 & 3 & 2 & 11 & 44 \\
\hline & CR & 0 & 1 & 0 & 0 & 1 & 0 & 0 & 0 & 0 & 0 & 1 \\
\hline \multirow[t]{4}{*}{ Analysis } & HA & 0 & 1 & 0 & 0 & 1 & 0 & 0 & 0 & 1 & 1 & 2 \\
\hline & TA & 1 & 5 & 5 & 4 & 15 & 8 & 13 & 4 & 8 & 33 & 48 \\
\hline & $\mathbf{R}$ & 13 & 13 & 6 & 15 & 47 & 9 & 6 & 4 & 10 & 29 & 76 \\
\hline & CR & 3 & 1 & 0 & 1 & 5 & 0 & 2 & 2 & 0 & 4 & 9 \\
\hline \multirow[t]{4}{*}{ Assignment } & HA & 3 & 1 & 0 & 1 & 5 & 0 & 0 & 0 & 1 & 1 & 6 \\
\hline & TA & 0 & 6 & 4 & 5 & 15 & 9 & 11 & 6 & 12 & 38 & 53 \\
\hline & $\mathbf{R}$ & 14 & 13 & 7 & 14 & 48 & 8 & 10 & 4 & 6 & 28 & 76 \\
\hline & $\mathrm{CR}^{2}$ & $\mathrm{n} / \mathrm{a}$ & $\mathrm{n} / \mathrm{a}$ & $\mathrm{n} / \mathrm{a}$ & $\mathrm{n} / \mathrm{a}$ & $n / a$ & $\mathrm{n} / \mathrm{a}$ & $\mathrm{n} / \mathrm{a}$ & $n / a$ & $\mathrm{n} / \mathrm{a}$ & $n / a$ & $n / a$ \\
\hline REFLECT & HA & 5 & 6 & 4 & 7 & 22 & 6 & 7 & 5 & 8 & 26 & 48 \\
\hline \multirow[t]{3}{*}{ TOTALS } & TA & 15 & 34 & 19 & 28 & 96 & 43 & 61 & 17 & 53 & 174 & 270 \\
\hline & $\mathbf{R}$ & 75 & 78 & 43 & 83 & 279 & 52 & 53 & 33 & 49 & 187 & 466 \\
\hline & CR & 7 & 2 & 0 & 2 & 11 & 1 & 5 & 5 & 4 & 15 & 26 \\
\hline Uncertainty & $\mathbf{P}$ & 3 & 11 & 4 & 12 & 30 & 8 & 12 & 5 & 11 & 36 & 66 \\
\hline \multirow[t]{3}{*}{ Orientation } & $\mathbf{N}$ & 4 & 0 & 1 & 1 & 6 & 0 & 2 & 0 & 0 & 2 & 8 \\
\hline & M & 5 & 5 & 3 & 4 & 16 & 4 & 4 & 4 & 5 & 17 & 33 \\
\hline & $\mathrm{NI} / \mathrm{U}$ & 5 & 5 & 3 & 3 & 16 & 5 & 3 & 1 & 3 & 12 & 28 \\
\hline
\end{tabular}

1=REFLECT criteria used during F13 did not differentiate between HA and TA, so TA only was coded; criteria modified for later semesters.

$2=$ REFLECT criteria did not differentiate between R and CR, so only R was coded for all semesters.

HA: habitual action (simple fact reporting and/or omission of major response elements)

TA: thoughtful action (elaborated narrative but remaining at the descriptive level)

R: reflection (effort to engage in meaning-making, analysis or some other aspect of reflection)

$\mathrm{CR}$ : critical reflection (comprehensive response that considers multiple interpretations or viewpoints) 


\section{Table 3: Revised REFLECT (Reflection Evaluation For Learners' Enhanced Competencies Tool) Rubric originally developed by Wald, et al (2012)}

\begin{tabular}{|c|c|c|c|c|}
\hline \multirow[b]{2}{*}{ Criterion } & \multicolumn{4}{|c|}{ Levels $^{1}$} \\
\hline & $\begin{array}{l}\text { Habitual action } \\
\text { (non-reflective) }\end{array}$ & $\begin{array}{l}\text { Thoughtful action } \\
\text { or introspection }\end{array}$ & Reflection & Critical reflection \\
\hline $\begin{array}{l}\text { Writing } \\
\text { spectrum }\end{array}$ & $\begin{array}{l}\text { Superficial descriptive } \\
\text { writing approach (fact } \\
\text { reporting, vague } \\
\text { impressions) without } \\
\text { reflection or } \\
\text { introspection }\end{array}$ & $\begin{array}{l}\text { Elaborated descriptive } \\
\text { writing approach and } \\
\text { impressions without } \\
\text { reflection }\end{array}$ & $\begin{array}{l}\text { Movement beyond } \\
\text { reporting or descriptive } \\
\text { writing to reflecting } \\
\text { (i.e., attempting to } \\
\text { understand, question, } \\
\text { or analyze the event) }\end{array}$ & $\begin{array}{l}\text { Exploration and critique } \\
\text { of assumptions, values, } \\
\text { beliefs, and/or biases, } \\
\text { and the consequences } \\
\text { of action (present and } \\
\text { future) }\end{array}$ \\
\hline Presence & $\begin{array}{l}\text { No sense of writer } \\
\text { being present }\end{array}$ & $\begin{array}{l}\text { Sense of writer being } \\
\text { partially present }\end{array}$ & $\begin{array}{l}\text { Sense of writer being } \\
\text { largely or fully present }\end{array}$ & $\begin{array}{l}\text { Sense of writer being } \\
\text { fully present }^{3}\end{array}$ \\
\hline $\begin{array}{l}\text { Description of } \\
\text { conflict or } \\
\text { disorienting } \\
\text { dilemma }\end{array}$ & $\begin{array}{l}\text { No description of the } \\
\text { disorienting dilemma, } \\
\text { conflict, challenge, or } \\
\text { issue of concern }\end{array}$ & $\begin{array}{l}\text { Absent or weak } \\
\text { description of the } \\
\text { disorienting dilemma, } \\
\text { conflict, challenge, or } \\
\text { issue of concern }\end{array}$ & $\begin{array}{l}\text { Description of the } \\
\text { disorienting dilemma, } \\
\text { conflict, challenge, or } \\
\text { issue of concern }\end{array}$ & $\begin{array}{l}\text { Full description of the } \\
\text { disorienting dilemma, } \\
\text { conflict, challenge, or } \\
\text { issue of concern that } \\
\text { includes multiple } \\
\text { perspectives, exploring } \\
\text { alternative } \\
\text { explanations, and } \\
\text { challenging } \\
\text { assumptions }\end{array}$ \\
\hline $\begin{array}{l}\text { Attending to } \\
\text { emotions }\end{array}$ & $\begin{array}{l}\text { Little or no recognition } \\
\text { or attention to } \\
\text { emotions }\end{array}$ & $\begin{array}{l}\text { Recognition but no } \\
\text { exploration or attention } \\
\text { to emotions }\end{array}$ & $\begin{array}{l}\text { Recognition, } \\
\text { exploration, and } \\
\text { attention to emotions }\end{array}$ & $\begin{array}{l}\text { Recognition, } \\
\text { exploration, attention } \\
\text { to emotions, and gain } \\
\text { of emotional insight }\end{array}$ \\
\hline $\begin{array}{l}\text { Analysis and } \\
\text { meaning } \\
\text { making }\end{array}$ & $\begin{array}{l}\text { No analysis or meaning } \\
\text { making }\end{array}$ & $\begin{array}{l}\text { Little or unclear analysis } \\
\text { or meaning making }\end{array}$ & $\begin{array}{l}\text { Some analysis and } \\
\text { meaning making }\end{array}$ & $\begin{array}{l}\text { Comprehensive analysis } \\
\text { and meaning making }\end{array}$ \\
\hline $\begin{array}{l}\text { Attention to } \\
\text { assignment }\end{array}$ & $\begin{array}{l}\text { Poorly addresses the } \\
\text { assignment question } \\
\text { and does not provide a } \\
\text { compelling rationale for } \\
\text { choosing an alternative }\end{array}$ & $\begin{array}{l}\text { Partial or unclear } \\
\text { addressing of } \\
\text { assignment question; } \\
\text { does not provide a } \\
\text { compelling rationale for } \\
\text { choosing an alternative }\end{array}$ & $\begin{array}{l}\text { Clearly answers the } \\
\text { assignment question or, } \\
\text { if relevant, provides a } \\
\text { compelling rationale for } \\
\text { choosing an alternative }\end{array}$ & $\begin{array}{l}\text { Clearly answers the } \\
\text { assignment question or, } \\
\text { if relevant provides a } \\
\text { compelling rationale for } \\
\text { choosing an alternative }^{4}\end{array}$ \\
\hline
\end{tabular}

\section{Notes:}

${ }^{1}$ The full REFLECT rubric also includes an optional Axis 2, which allows for further assessment of responses that are deemed as critical reflection for the writing spectrum criterion. The Axis 2 levels include transformational learning or confirmatory learning. Because of the low number of responses that were coded as critical reflection for the writing spectrum criterion in this study, we did not include Axis 2 in our results or analysis.

${ }^{2}$ The original descriptions for habitual action and thoughtful action for the presence criterion were identical, so we revised the habitual action to read "No sense of the writer being present" for the purposes of this study.

${ }^{3}$ The descriptions for reflection and critical reflection for the presence criterion are not mutually exclusive, so we collapsed these categories as reflection for the purposes of this study.

${ }^{4}$ The descriptions for reflection and critical reflection for the attention to assignment criterion are identical, so we collapsed these categories as reflection for the purposes of this study. 
Figure 1: Reflection levels aggregated from both prompts (as percentages)

\section{Level of Engagement}
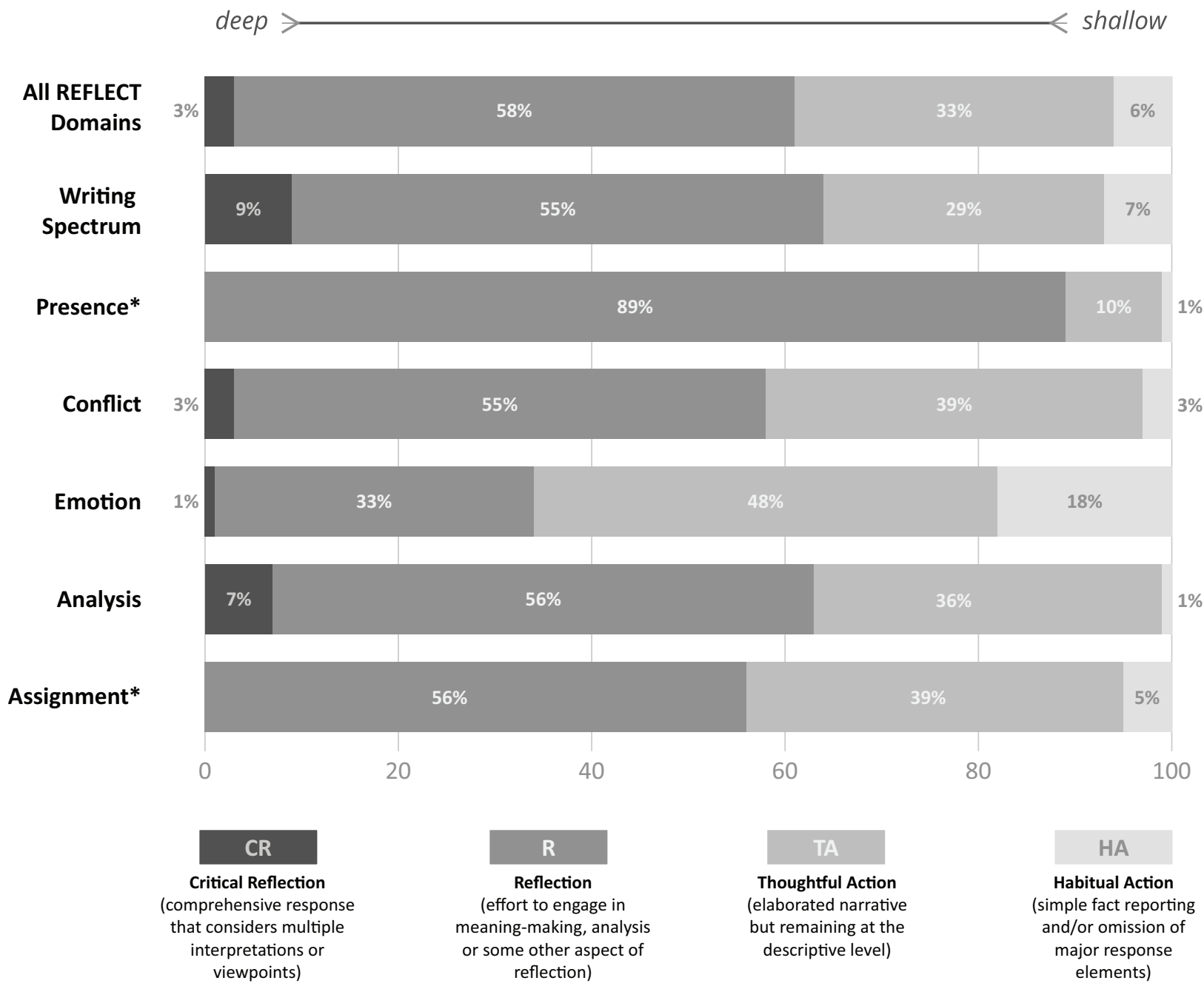

General note: As a result of rounding, some percentages may not appear to add up to $100 \%$. * The Presence and Assignment dimensions did not include critical reflection as a coding option. 
Figure 2: Comparative reflection levels for both prompts (displayed as percentages)

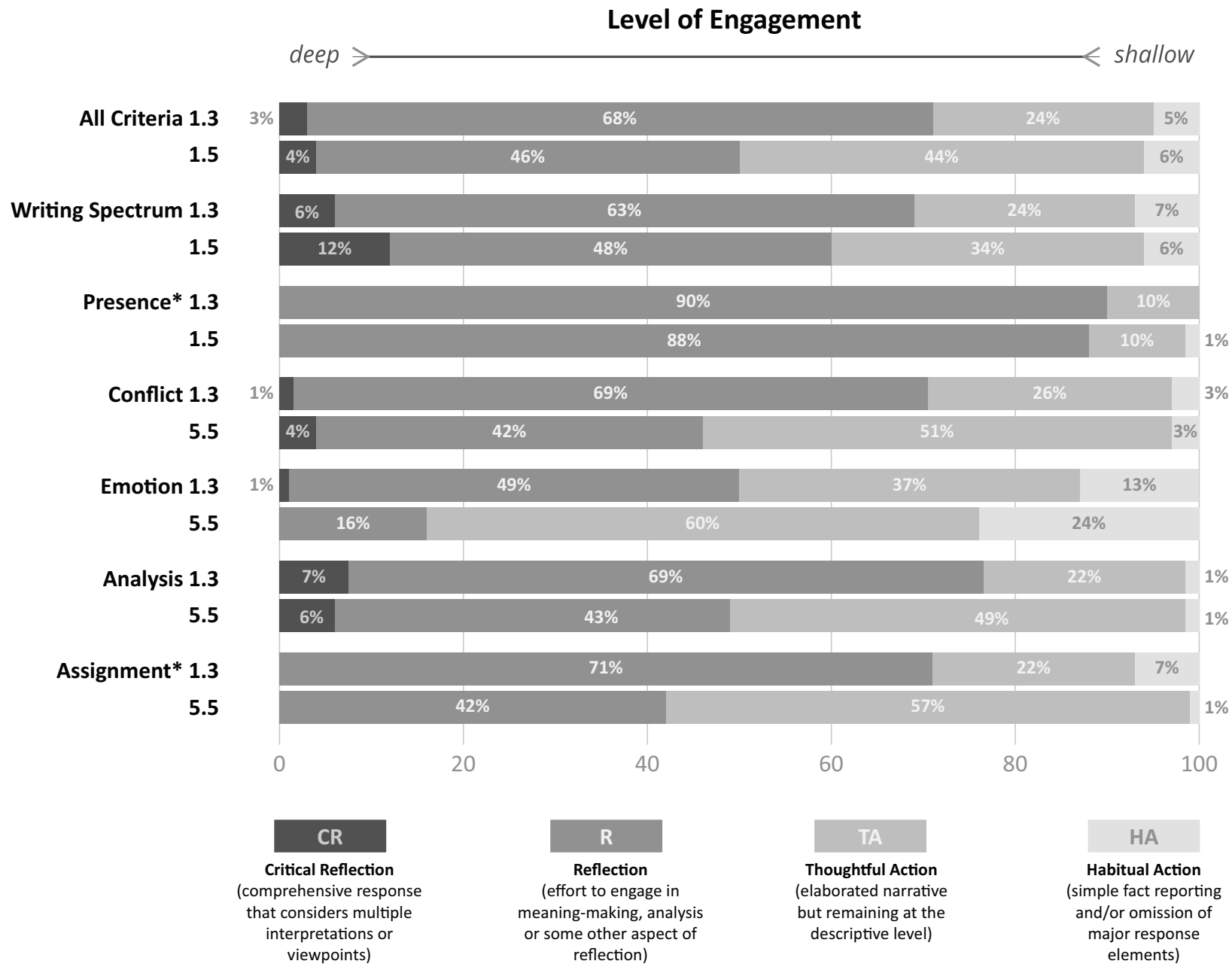


Figure 3: Uncertainty orientation by prompt (displayed as percentages)

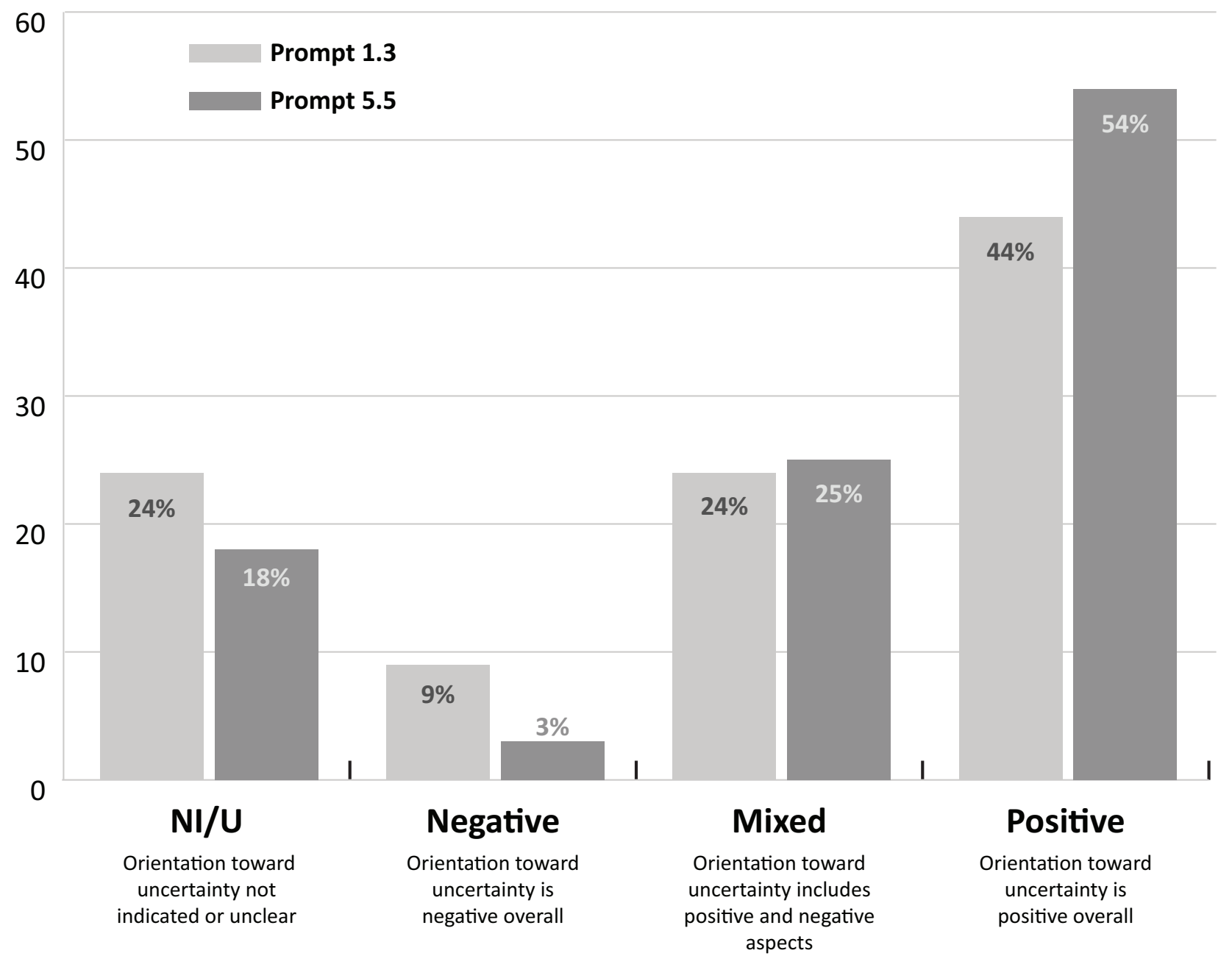

